\title{
Biobanking strategies and regulative approaches in the EU: recent perspectives
}

This article was published in the following Dove Press journal:

Journal of Biorepository Science for Applied Medicine

16 October 2015

Number of times this article has been viewed

\section{Katharina Beier' \\ Christian Lenk ${ }^{2}$ \\ 'Department of Medical Ethics and History of Medicine, University Medical Center Göttingen, Göttingen, Germany; ${ }^{2}$ Institute of the History, Philosophy, and Ethics of Medicine, Ulm University, Ulm, Germany}

\begin{abstract}
Biobanks, ie, systematic collections of human biological materials and associated clinical and lifestyle data, provide an indispensable infrastructure for modern research. Although biobank research takes place on a global scale, there is no internationally binding framework for its ethical and legal regulation yet. A better understanding of existing regulative approaches is an important prerequisite for its ethical and legal harmonization and, thus, for improving the interoperability of biobank-based research in the future. This review focuses on biobanking strategies, regulative approaches, and recent developments in Europe. Specifically, we discuss selected ethical and legal issues in research biobanking in the European context by looking at population biobanks, new participation models, the cross-border sharing of samples, the participation of minors, the handling of incidental health findings, whole genome sequencing, and commercialization. We also provide an overview of regulations on biobank research in the EU and member states and highlight commonalities and differences. Although several common trends can be identified across Europe, we acknowledge the importance of national research traditions that cannot easily be set aside. Thus, harmonization, rather than a complete unification, of approach seems to be the most realistic vision for future biobank research in Europe.
\end{abstract}

Keywords: population biobanks, cross-border sharing, minors, whole genome sequencing, incidental health findings, commercialization, ethical and legal issues

\section{Introduction}

Biobanks, ie, systematic collections of human biological materials and associated clinical and lifestyle data, provide an indispensable infrastructure for modern research. However, a number of ethical and legal challenges arise over the obtaining, use, and sharing of specimens and data. One widely discussed issue is the limits of informed consent (IC), but new questions emerge with advances in biotechnologies, particularly in the fields of genetic analysis and data processing. For example, genome-wide association studies may increase the risk of reidentifying subjects and violate their privacy. In addition, with the possibility that the cost of whole genome sequencing (WGS) will decrease, novel issues, eg, informing subjects, or their families, of incidental health findings (IHFs), become pressing. With biobanks' growing significance in the field of personalized medicine, ${ }^{1}$ the boundary between research and health becomes more blurred.

Although biobank research takes place on a global scale, there is no internationally binding framework of ethical and legal regulation yet. A better understanding of existing regulatory approaches is an important prerequisite for such international agreement. In this review, we focus on biobanking in the countries of the EU. Europe's significant
Correspondence: Katharina Beier Department of Medical Ethics and History of Medicine, University Medical Center Göttingen, Humboldtallee 36, 37073 Göttingen, Germany

$\mathrm{Tel}+4955 \mathrm{I} 394$ I84

Fax +49 55I 399554 Email katharina.beier@medizin.unigoettingen.de
Journal of Biorepository Science for Applied Medicine 20I5:3 69-8I (c) (i) (5) 2015 Beier and Lenk. This work is published by Dove Medical Press Limited, and licensed under Creative Commons Attribution - Non Commercial (unported, v3.0) permission from Dove Medical Press Limited, provided the work is properly attributed. Permissions beyond the scope of the License are administered by Dove Medical Press Limited. Information on permission from Dove Medical Press Limited, provided the work is properly attributed. P
how to request permission may be found at: http://www.dovepress.com/permissions.php 
role in this field is the result of national health care systems that facilitate the collection of biological materials and keep reliable health records ${ }^{2}$ and of a long-standing tradition of epidemiological research, particularly in the northern countries. For these same reasons, European biobanks are well suited to studying the causes of complex diseases.

In what follows, we discuss selected fields of biobank research from an ethical and a legal perspective, specifically, population biobanks, ethical frameworks for biobank participation, the cross-border sharing of samples, the involvement of minors, the handling of IHFs, the consequences of WGS, and the role of commercialization. Furthermore, we describe the European state of the art by analyzing present EU and national frameworks for biobank research and pointing out commonalities and differences among the EU's states.

\section{Definitions of biobanks and European biobanking activities}

In the biobank community, there is agreement neither on the definition and classification of biobanks ${ }^{3}$ nor on biobanking terminology. ${ }^{4}$ Hewitt and Watson, ${ }^{5}$ for example, define a biobank as a facility that provides material for scientific and clinical use. In contrast, Shaw et $\mathrm{al}^{6}$ restrict the term "biobank" to facilities whose purpose is research.

European definitions reflect this same disagreement. While in Belgian law, ${ }^{7}$ for example, the term "biobank" is restricted to research facilities, in the Portuguese statute it also refers to collections established for health care, screening programs, or research purposes. ${ }^{8}$ European biobank definitions also cover storage times, identification of sample donors, genealogical linkage, and the legal status of biobanks.

The lack of a common definition is not just a problem of nomenclature. For researchers, it impedes the identification of relevant samples, interferes with collaboration among biobanks, and is an obstacle to regulative harmonization. It also creates ethical problems. For example, interviews with international biobanking experts working in Switzerland revealed that they use definitional loopholes strategically to circumvent the stricter requirements on institutions that qualify legally as "biobanks". 6

Beyond this terminological heterogeneity, which will likely persist, population- and disease-specific collections are still recognized as "major biobank formats" in Europe. 9 According to a recent survey of 126 biobanks in 23 European countries, the majority are disease-specific and maintain small collections (between 1,000 and 10,000 samples). ${ }^{10}$ But Europe also has a range of large population biobanks. Beyond these two dimensions, European biobanks are multifarious in focus, types of samples collected, and organizational structure. ${ }^{11}$

A worldwide overview reveals that Europe includes a great many biobanking networks. ${ }^{12}$ While the majority are national, the EU Framework Programmes fund some international infrastructure initiatives. ${ }^{10,13}$ As with biobanks, biobank networks differ from one another with regard to their purposes and organizational structures. ${ }^{14,15}$

The largest initiative for connecting existing and planned biobanks in Europe is the Biobanking and Biomolecular Resources Research Infrastructure (BBMRI). In 2013, it became EU's official legal framework for a European Research Infrastructure Consortium (BBMRI-ERIC). BBMRI-ERIC is a consortium with more than 50 members and over 280 associated organizations (mostly biobanks) from more than 30 countries. It is meant to facilitate access to quality-controlled biological resources and biomedical facilities "by pulling together biobanks and biomolecular resources into a pan-European facility"16 on a not-for-profit basis. Though BBMRI-ERIC promotes common standards for biobanking, it is not expected that it will be able to overcome the regulatory diversity in European biobanking. ${ }^{16,17}$

Although researchers worldwide recognize European biobanks as important resources, obstacles to their efficient use exist. Critical points are the fragmentation of sample collections and a lack of harmony among technical, ethical, and legal requirements. To promote future harmony, the EU-funded project Tiss. EU has provided an extensive overview and analysis of current ethical and legal approaches in Europe. ${ }^{18,19}$ While we will discuss the details of the European regulative framework below, some pertinent European and EU instruments that impact current approaches and regulations in biobanking are specified in Table 1.

\section{European biobanking approaches and developments in selected fields Population biobanks}

After Iceland had set up its Health Sector Database at the beginning of the 21 st century, other countries began national population biobanks, eg, the UK, Sweden, Latvia, and Estonia. The importance of population biobanks is underscored by the fact that specific regulations for them already exist. $\operatorname{Rec}(2006) 4$ (Recommendation Rec(2006)4 of the Committee of Ministers to member states on research on biological materials of human origin) includes a chapter on the subject, ${ }^{20}$ and some countries passed specific population biobank laws, for example, Estonia's Human Genes Research Act, before beginning their national biobanks. 
Table I Regulations being relevant for biobank research at European and EU levels

\begin{tabular}{|c|c|}
\hline Regulative documents & Regulative scope \\
\hline $\begin{array}{l}\text { European Parliament and Council: Directive 1995/46/EC on the } \\
\text { protection of individuals with regard to the processing of personal } \\
\text { data and on the free movement of such data, } 1995 \text { (Directive) }\end{array}$ & $\begin{array}{l}\text { The Directive covers the processing of identifiable data of natural persons } \\
\text { (eg, patients, registered donors, etc). The Directive had to be transposed } \\
\text { into national law by the EU member states by the end of } 1998 \text {. }\end{array}$ \\
\hline $\begin{array}{l}\text { Council of Europe: Convention for the Protection of Human Rights } \\
\text { and Dignity of the Human Being with regard to the Application of } \\
\text { Biology and Medicine: Convention on Human Rights and Biomedicine, } \\
\text { (OC) } 1997 \text { (The OC) })^{51}\end{array}$ & $\begin{array}{l}\text { The OC, which has been ratified by } 29 \text { countries so far, is an international } \\
\text { and multilaterally binding instrument that aims at the prevention of misuse } \\
\text { in the field of biomedicine and research. It creates a minimum common } \\
\text { standard while allowing states to legislate for a greater degree } \\
\text { of protection upon ratification. }\end{array}$ \\
\hline $\begin{array}{l}\text { Council of Europe: Recommendation } \operatorname{Rec}(2006) 4 \text { of the Committee of } \\
\text { Ministers to member states on research on biological materials of } \\
\text { human origin, } 2006(\operatorname{Rec}(2006) 4)^{20}\end{array}$ & $\begin{array}{l}\text { Rec(2006) } 4 \text { applies to the full range of research activities in the field of } \\
\text { health involving human biological materials, except fetal and embryonic } \\
\text { tissues. Governments of member states are asked to adapt their laws } \\
\text { and practices to the provisions and promote the establishment of practice } \\
\text { guidelines in line with the recommendation. }\end{array}$ \\
\hline
\end{tabular}

Abbreviation: OC, Oviedo Convention.

In addition to collections based on national populations, there are also population biobanks that focus on local communities, eg, PopGen in Germany and the Nord-Trøndelag Health Study (HUNT) in Norway. Analyses of different approaches to population biobanking in Europe ${ }^{21}$ provide instructive examples for setting up population biobanks in other countries..$^{22}$ At present, however, the establishment of new population biobanks seems to have slowed as the consolidation and networking of existing biobanks have gained in importance.

Increasingly sophisticated methods of sample analysis have made the quality of samples more important than their quantity. For example, Croatia's National Biobank aims at dense genome-wide scans, with hundreds of thousands of genomic markers, followed by sequencing for the moderate number of 10,001 healthy participants. ${ }^{23}$ The more recently started National Cohort Study in Germany will collect comprehensive lifestyle, sociodemographic, medical, and health data using a wide range of examinations and diagnostics including wholebody magnetic resonance tomography and brain scans, on 200,000 participants over approximately 25 years. ${ }^{24}$

Even ambitious projects seem to end up with moderate sample numbers. The Estonian Genome Project's original target of 1 million participants was reduced to 100,000 by 2010 . At present, the projected number is even smaller, with 52,000 samples collected so far.

Another trend that Estonia exemplifies is "a clear tendency to bring genetic databases under the auspices of public universities and use direct public funding". ${ }^{25}$ Estonia's database started as a private foundation in the framework of a nongovernmental organization as this "seemed to enable the involvement of private funding without many regulatory problems". ${ }^{26}$ However, this framework failed. An amendment to the Human Genes Research Act in 2007 secured the future of the Estonia Genome Project. Today, it is a publically funded structural unit of the University of Tartu.

In Sweden, the LifeGene project, which aims to collect samples and health data from 500,000 Swedes between 0 and 45 years of age, has recently triggered a debate about population biobanking data. When a Research Ethics Committee (REC) declared that it was not competent to judge the ethics of LifeGene, because it would not be a specific research project but a research infrastructure, the Data Inspection Board concluded that there was no legal basis for the project, and it fell into a legal limbo. The issue was preliminarily resolved by the passage of a law about "Health research on environmental and genetic causes of diseases" (SFS 2013:794), which is valid until December 2015, that allows Swedish universities to create research registers provided that the sources of data give their explicit consent. Nevertheless, the government has initiated a public inquiry into register research. A revision of the Swedish biobank act is currently pending, and further changes in the legal framework may follow.

\section{Ethical frameworks for participation in biobank research}

Not least because of criticism of the Icelandic Health Sector Database, ${ }^{27}$ population biobanks, and biobanks in general, have become more sensitive to the attitudes of the public. Thus, while data quantity and quality were the crucial concerns in the early years of biobanking, consideration of the views of external stakeholders (eg, patients/donors and research customers and funders) characterizes its present stage. $^{28}$

Empirical studies show that Europeans are very willing to participate in biobank research, mostly for altruistic reasons. ${ }^{29,30}$ However, contextual factors, such as people's 
general trust in political and other institutions, impact perceptions of biobank research. ${ }^{31}$ People in the Nordic welfare states, for example, regard participating in research as their civic duty, a contribution to the common good. ${ }^{32} \mathrm{~A}$ comparative study of breast cancer patients in Belgium, Germany, and the UK showed that perceptions of medical science and of national standards of data protection also shape donors' attitudes toward biobank research to a large extent..$^{33}$

At present, new models of the interactions among researchers, donors, and the general public are under discussion. ${ }^{34}$ According to a recent report from the BBMRI, for example, biobanks are no longer perceived as "simply service institutions for the scientific community", but as "active agents" for their donors..$^{35}$ Moreover, the limitations of IC in biobank research have resulted in new conceptions of IC, eg, blanket consent, broad consent, and authorization models. ${ }^{36,37}$ And, given the effects that biobank research has on third parties, eg, family members and whole communities, group models of consent have also been suggested. ${ }^{38}$ More recently, dynamic consent is being discussed as "a new approach for engaging individuals about the use of their personal information". ${ }^{39}$ According to Kaye et al, ${ }^{39}$ dynamic consent is an "interactive personalized interface that allows participants to engage as much or as little as they choose and to alter their consent choices in real time". But whether dynamic consent really enjoys advantages over broad consent is currently controversial..$^{40}$

Though debates over consent are still largely framed in individualistic terminology, alternative frameworks for participation are gaining importance. Solidarity and trust, both of which create a sense of reciprocity, are two high-profile candidates. The framework of solidarity reflects people's willingness to accept certain costs for their participation in biobank research in order to help others. ${ }^{41} \mathrm{~A}$ trust framework builds on a mutual relationship insofar as it acknowledges the personal contribution of donors. ${ }^{42}$ Specifically, the trust that donors express by their participation imposes moral obligations on researchers, for example, with regard to the proper use and confidential treatment of samples. ${ }^{43}$ In order to build trust, adequate mechanisms for the governance and oversight of biobanks must be in place. The dynamic participation model has elements in common with the trust and solidarity models insofar as all three approaches aim at a revision of the asymmetric relationship between researchers and participants. However, in contrast to the dynamic consent approach, where the majority of decisions are left up to the individual donor, at least in principle, solidarity- and trust-based approaches rely on more general governance mechanisms, eg, independent oversight. ${ }^{41}$ Although a closer relationship is likely to foster the ends of both researchers and donors, it has been noted that "the closer the relationship, the more obligations and expectations exist on both sides". Therefore, the benefits of a closer relationship must be weighed carefully against its potential costs. ${ }^{44}$

\section{International sharing of samples}

The sharing of biobank samples across national borders is critical to realizing the full potential of biobanking. However, several obstacles to sample sharing leave European biobanks underutilized. In fact, $20 \%$ of the biobanks surveyed in the study of Zika et $\mathrm{al}^{10}$ are only accessed by researchers who collected the samples, and in $10 \%$ access was restricted to researchers within the institute. An analysis of the literature has identified logistical, ethical, psychological, and legal obstacles to international sharing among biobanks. ${ }^{45}$

A lack of information on available samples, so that other researchers cannot request them, is one logistical obstacle. Quality differences among samples and the lack of standardization in their processing are two others. Divergent consent regimes, among other causes, create ethical roadblocks to sample sharing. The sharing of data, in addition to samples, can also be ethically difficult because of the obligation to treat them confidentially. ${ }^{45}$ The fact that many researchers are directly involved in building up a biobank erects a psychological barrier to their sharing "their" samples with researchers abroad. A system of rewards could mitigate this problem to a certain extent, ${ }^{46}$ but it cannot be expected to overcome the "elitism and competition" that foster attitudes of "territoriality" among researchers. ${ }^{45}$

Legal barriers, ie, the diversity and incompatibility of different countries' legal provisions, are by far the greatest obstructions to sample sharing. ${ }^{18,19,47}$ While Rec(2006)4 merely states that "Biological materials and associated personal data should only be transferred to another state if that state ensures an adequate level of protection" (article 16), ${ }^{20}$ several countries regulate international sharing more strictly. For example, Hungary and Estonia simply do not allow the transfer of samples abroad. In Sweden and Norway, approval by an REC is required before Swedish/Norwegian samples can be analyzed abroad, but they may not be stored in another nation's biobank for longer than the analysis requires. ${ }^{48} \mathrm{In}$ contrast, Spanish biobanks are permitted to release samples to any researcher, public or private. As many countries have no explicit law governing international sample sharing, the implementation of a material transfer agreement is currently considered best practice. Material transfer agreements 
may regulate intellectual property rights, define the scope of research, and restrict the commercial use of samples. ${ }^{49}$ Although the harmonization of legal rules remains a task for the future, the first steps have been taken by BBMRI-ERIC, among others that make country-specific information available to researchers worldwide.

\section{Minors in biobank research}

A central ethical and legal issue in the medical treatment of children and adolescents is their competence for informed decision-making. Today, it is widely acknowledged that the ability of minors to assess information about a treatment or a research project does not depend primarily on their age, but on their maturity and competence in understanding its meaning, scope, and possible side effects. ${ }^{50}$ In the case of diminished capacity or incompetence, parents or guardians must decide for the minor. However, overly strict or demanding requirements for the IC of research participants can exclude whole populations from innovative research projects. Therefore, the justification of minors' participation in research should depend on the concrete benefit they can expect from it.

In the course of the ratification of the Oviedo Convention (OC), the critique of the potential overprotection of children and adolescents (and other vulnerable populations) led to a liberalization of ethical and legal requirements for IC in research with minors in the countries of the EU. Articles 6 and 17 allow that persons who are not able to give their consent can still participate in research projects provided that their legal representatives are properly informed and give their consent. They also require that the person does not object to participation, that the research results "have the potential to produce real and direct benefit to his or her health" (article $[17], 1$, ii) or "to other persons in the same age category or afflicted with the same disease or disorder or having the same condition" (article [17], 2, i), and that "the research entails only minimal risk and minimal burden for the individual concerned" (article [17], 2, ii). ${ }^{51}$

Given these principles for the participation of children and adolescents in biobank research, the following questions must be addressed:

1. How can sufficient information be provided to children and adolescents?

2. Are children and adolescents able to give consent, or must their parents or legal representatives consent to their study participation?

3. Is it correct to assume that participation in biobank research is acceptable to persons who are not competent to give consent, particularly if the research contributes mainly to basic science?

4. What risks and burdens does a research project impose, and can any benefit be expected for the participating child or adolescent?

Reply: 1) Nowadays, it is common practice to inform children from the age of seven on about a research project in language and using descriptions that are suitable for their age. However, providing children with information about a research project is one thing; ensuring their assent/consent to participation is another. In fact, some pediatricians criticize the practice of having children between the ages of seven and thirteen sign a consent form, because children can misperceive their consent as a contract that binds them to participating. ${ }^{52}$

Reply: 2) In Europe, a child's or adolescent's assent/ consent to participate in a study must usually be accompanied by the consent of his/her parents or legal representatives. However, the justifiability provision is not self-evident, for adolescents are commonly held to have the right to visit a physician and receive treatment without the knowledge of their parents as, for example, with the prescription of contraceptives.

Reply: 3) Medical ethics and the law, in general, and the $\mathrm{OC}$, in particular, presuppose that participation in research with the potential for direct benefits to subjects is justifiable, and even preferable, for noncompetent persons provided that their legal representatives agree to the specific research project. In contrast, participation in research without any potential benefit for a noncompetent subject can be legitimate only under the condition that the research imposes only minimal burden and risk on the subject. This provision is obligatory and applies even when parents or legal representatives give their consent.

Reply: 4) Clinical researchers sometimes argue that biobank research imposes no burden or risk, especially when biomaterial is obtained during a surgery performed for therapeutic reasons and the residual material is no longer needed for diagnosis. However, researchers do have to justify "minor" interventions and extractions of body material in terms of ethical and legal principles, and the assent/consent of the child or adolescent and his/her parents or guardian is necessary. Regarding risk assessment, it is important to note that the EU's Ad Hoc Group's Ethical Considerations for Clinical Trials on Medicinal Products Conducted with the Paediatric Population (Annex 4) specifies that "arterial puncture", "peripheral venous lines", and "skin punch biopsy" (among other procedures) are interventions that 
involve more than "minimal risk" (ie, a "minor increase over minimal risk"). ${ }^{53}$ Consequently, these interventions are not permissible in a study without any direct benefit for the participating child.

The transfer of personal data in the context of biobank research constitutes a further risk for minors. In fact, the worldwide transfer and communication of patient or subject data may compromise patients' rights to data protection. It is therefore important that when data of European participants are transferred to other institutions or countries, biobanks follow the EU's standards for data protection, and also if their data are used outside of the EU. Mutual agreements among international research consortiums regarding the handling of data and biomaterial are an important tool to ensure this. ${ }^{47}$ Additionally, the transfer of personal data to unauthorized persons or institutions, such as insurers, employers, and other private or commercial enterprises interested in private data, must be prohibited, not least because in some countries insurees are obliged to inform their insurers about medical diagnoses. Therefore, if a minor's participation in a biobank research project results in a predictive genetic diagnosis; it could prevent him or her from procuring insurance later. Adequate information about these potential adverse consequences of biobank research must be provided to participants, in general, and to children and their representatives, in particular.

\section{Whole genome sequencing}

In addition to the development of new genetic tests, the introduction of WGS into genetics and biobank research is one of the most significant changes in recent research. As van $\mathrm{El}$ et $\mathrm{al}^{54}$ point out, WGS is not just an additional methodological option, but it has the potential to influence diagnostic practices broadly and even to change the entire approach of medical genetics:

Until recently, a diagnostic genetic test tended to focus on one specific question. In the case of a clinical suspicion of a monogenic condition, DNA analysis of one or a few specific genes was performed, whereas in cytogenetics, the whole genome was analysed at a relatively low resolution of 5-10 Mb to answer a defined clinical question. Increasingly, however, diagnostic tests now look at a large panel of genes (eg, genes implied in cardiovascular events) via microarrays, a relatively targeted approach. In addition, non-targeted high-resolution next-generation sequencing techniques may be applied, detecting mutations throughout the genome. ${ }^{54}$
The authors conclude that in population screening, for example:

The question would no longer be which target diseases should be included in the test panel, but which should be excluded by selective analysis of WGS/WES [whole exome sequencing] data. ${ }^{54}$

As their examples suggest, a scientific revolution concerning the availability of genetic data may be in the offing. While the current situation is marked by a general scarcity of genetic information, comprehensively documented genome data on each patient will become the future medical standard. In contrast to general ethical concerns about the transparent patient, current principles in medical ethics and the law require that an individual receive detailed information and give IC for each specific genetic test undergone, rather than a single IC for a multitude of tests that are only loosely related to the disease entity in question. For example, article 8(1) of the Council of Europe's Additional Protocol to the Convention on Human Rights and Biomedicine, concerning Genetic Testing for Health Purposes, the focus of which is diagnostics, demands that:

When a genetic test is envisaged, the person concerned shall be provided with prior appropriate information in particular on the purpose and the nature of the test, as well as the implications of its results. ${ }^{55}$

While it is easy to meet this requirement for tests that aim at a single genetic predisposition, it will be difficult, or even impossible, to meet it in the context of biobank research with data and genetic information from WGS. Additionally, the availability of qualified genetic counseling is obligatory, as in the diagnostic setting, which raises the question of what standards for genetic counseling will apply in the context of biobank research when WGS becomes standard. For example, article 12 of the $\mathrm{OC}$ explicitly requires the availability of appropriate genetic counseling for all kinds of genetic testing (ie, for diagnostic and research purposes):

Tests which are predictive of genetic diseases or which serve either to identify the subject as a carrier of a gene responsible for a disease or to detect a genetic predisposition or susceptibility to a disease may be performed only for health purposes or for scientific research linked to health purposes, and subject to appropriate genetic counselling. ${ }^{51}$

This also applies to WGS in the course of genetic research, which is confirmed by article 32 of the Explanatory Report to the Additional Protocol to the Convention on 
Human Rights and Biomedicine, concerning Genetic Testing for Health Purposes. ${ }^{56}$

In the European regulatory context, WGS must thus be seen in terms of genetic diagnosis and research. Also, individual institutions have published recommendations for the ethical and legal regulation of WGS. In Germany, for example, Cornerstones for a Heidelberg Practice of Whole Genome Sequencing ${ }^{57}$ is based on general principles of medical ethics, eg, patient autonomy, nondiscrimination, privacy and confidentiality, and noncommercialization, as well as on more specific rules for biobank and tissue research, like societal benefit, the protection of future generations, and the handling of body materials.

\section{Incidental health findings}

One important implication of WGS is that broad and nonspecific diagnostic and research procedures will produce more unintended so-called IHFs. How these should be handled in biobank research is a crucial question. As with biobank research in general, there is no binding European regulation on this matter. However, in certain specified cases, professional societies recognize that it is the duty of researchers and physicians to disclose IHFs to patients and research subjects. Hence, it is sometimes suggested that IHFs be categorized according to their relevance for the individual patient. The recommendations of the German Society for Human Genetics, for example, distinguish four categories of IHFs ${ }^{58}$ (Table 2).

Specifically, the German Society for Human Genetics recommends that IHFs of category (1) be communicated to the person concerned in accordance with her preferences. This is seen as part of the physician's or geneticist's professional duty of care. The disclosure of IHFs in the other categories should be handled on a case-by-case basis. However, the communication of findings from category (3), where no reasonable preventative measures exist, is not recom-

Table 2 Different categories of incidental findings according to the German Society for Human Genetics 2013 (translation by the authors)

Category I: Genetic characteristics that show a relevant risk for disease for which an effective therapy or effective preventative measures exist. Category 2: Genetic characteristics that show a relevant risk for a disease that cannot be treated at the time of diagnosis.

Category 3: Genetic characteristics that increase the risk of the occurrence of a disease only slightly, for example, data from genomewide association studies on multifactor diseases.

Category 4: Genetic characteristics that impose no health risks on the person who undergoes the test but that can lead to disease in the offspring and/or indicate disease in relatives and can therefore influence family planning.

Note: Translated from reference. ${ }^{58}$ mended. This will probably apply to the majority of findings resulting from future biobank research, although it will also regularly produce findings of category (1).

Ethical and legal problems for handling IHFs and genetic diagnoses also arise with regard to relatives who were not tested, especially when effective preventive measures exist. In this context, the UK's Royal College of Physicians urges the presumption of "genetic solidarity". For persons who undergo genetic testing, this implies a duty (in close cooperation with the physician or geneticist) to use their test results within the family in a reasonable way, for example, to enable disease prevention, if possible ${ }^{59}$ (detailed discussion ${ }^{60}$ ).

Taken together, the prior examples show that a careful approach to IHFs is needed. In particular, a distinction must be drawn between findings that are relevant to the patient's health and that should be disclosed and those without any therapeutic relevance that should not be communicated. The ethical and legal acceptability of research will increase once questions concerning the communication of IHFs are standardly addressed before the start of research projects and local biobank regulations for IHFs are regularly updated. This would also be in line with the demand of the Declaration of Helsinki to specify explicitly the potential benefits for participants in medical research (articles 22, 34), ${ }^{61}$ given that the communication of verified IHFs can be seen as a benefit. In the end, an effective procedure for informing participants about specified findings will probably strengthen their motivation to undergo diagnostic measures in biobank research - an effect that will benefit biobanks and cooperating researchers. ${ }^{62}$

\section{Commercialization}

The considerable costs of establishing and maintaining biobanks increasingly render the involvement of private entities unavoidable. With regard to its ethical and legal implications, however, commercialization of biobank research, ie, "the transfer of property on body material in exchange for financial rewards", ${ }^{63}$ is controversial. Although this debate is global, ${ }^{64}$ the European discourse displays some special features. As empirical studies have shown, Europeans are reluctant to allow commercial use of their samples. However, this reluctance may not persist once donors realize that commercial motives do not endanger the realization of the common good. ${ }^{65}$

In legal terms, article 21 of the OC and article 7 of the $\operatorname{Rec}(2006) 4$ stipulate that "the human body and its parts" and "biological materials", respectively, "should not, as such, give rise to financial gain". ${ }^{51,20}$ However, the practical meaning of this prescription is far from clear and may vary 
from context to context. ${ }^{65-68}$ In fact, the gradual introduction of commercialization can already be observed insofar as bodily materials can be procured, exchanged, and traded in several European countries as long as these activities produce no financial gain. ${ }^{63,69}$ Moreover, several biobank networks charge researchers fees beyond what is needed to recover their costs. ${ }^{15}$ The no-commercialization principle will definitely become obsolete in Europe if human biological materials are turned into products. The difficulties this may bring, for example, for donors' and patients' access to samples have been highlighted in an open letter to EU policy makers. ${ }^{68}$

The issue of commercialization is closely linked to questions of ownership of and property rights to human biological materials. Most European countries are reluctant to grant donors property rights as the human body and its parts are conceived as res extra commercium in both the Continental civil law and English common law traditions. Strict adherence to this principle, however, is complicated by the fact that tissue donation seems to require property rights, given that one can donate only what one owns. In addition, implementation of the no-property principle varies across the EUs' member states. Although some countries explicitly deny property rights (eg, France), Bellevier and Noiville ${ }^{70}$ have argued that "the property-based conception of the relation between the person and her own body may be gaining ground". For example, in the UK, the no-property principle was weakened by the court's acknowledgment that six plaintiffs' loss of their frozen sperm constituted material damage. ${ }^{71}$ Other countries grant ownership rights not to donors but to the biobank (eg, Greece and Belgium) or the chief processor of the sample (eg, Estonia). Finally, some countries do grant property rights to donors (eg, Portugal) or acknowledge at least de facto property rights by referring to donors' personality rights (eg, German, Austria, and Switzerland). In this latter case, research with tissues may require a prior transfer of the donor's ownership of her tissues to the biobank.

Although the bulk of European biobanks are publicly owned, ${ }^{10}$ commercial practices are gaining ground. Given the complex relationships between bodily materials and their human sources and the increasing forms of commercial activity, it is important to consider these issues adequately in public discussion and in crafting legal provisions. ${ }^{63}$ Moreover, the dichotomous conception of bodily materials as belonging to either the sphere of donation or the sphere of the market is outdated and must be replaced by more nuanced models. ${ }^{72}$ For example, the not-for-profit status of charitable institutions and public-private partnerships could, together with public funding, help to ensure the financial sustainability of biobanks. However, whether public-private partnerships can succeed in aligning the interests of researchers, commercial actors, and donors, a decisive question for the future of biobank research, is yet not clear. ${ }^{73}$

\section{Regulation at the EU level}

One striking reason for the diversity in the regulation of biobank research is the lack of a binding European convention. For example, Directive 2004/23/EC of the European Parliament and Council covers only quality and safety in the therapeutic use and transplantation of tissues; it says nothing about research. However, some of the EU's conventions and directives impact member states' regulative approaches. ${ }^{42,63}$ The European Convention on Human Rights and Biomedicine, referred to in the following as the $\mathrm{OC},{ }^{51}$ which was ratified by the majority of European countries, contains several provisions that are relevant for biobank research. For one, the OC stipulates that IC is a general rule for research (article 16) and requires a subject's renewed (secondary) consent if her samples will be used for purposes that were not covered by her initial consent (article 22).

The $\operatorname{Rec}(2006) 4^{20}$ was the first official European statement applying to research with human biological materials. Though not legally binding, it provides orientation, especially in countries without domestic regulations, on a range of issues. ${ }^{74}$ For example, it specifies rules for obtaining renewed consent in cases of identifiable biological materials (article 22) and changing the scope of or withdrawing one's consent (article 15). It also offers a definition of the "identifiability" of biological materials and prescribes that research with nonidentifiable materials take priority over the use of identifiable ones (article 8). Finally, it covers organizational issues (eg, responsibility for and access to a collection and quality-assurance measures) (article 14) and population biobanks (articles 17-20). ${ }^{20}$

The European Commission's and Council's European Data Protection Directive (1995/46/EC), which has been implemented by all EU members, is also relevant to biobanking, since research with biobanked tissues involves the processing of personal data. The Directive grants a subject from whom data are collected the right to information about the storage of her data, their processing, and their recipients (article 10). Article 6(1) stipulates that personal data may be collected and processed only "for specified, explicit and legitimate purposes". Data that are further processed only 
"for historical, statistical or scientific purposes shall not be considered as incompatible provided that Member States provide appropriate safeguards". In the context of research, however, articles 8(3) and 11(2) allow for exceptions with regard to a subject's consent and the use of her data provided that the processor of the data is bound by a professional obligation of confidentiality. ${ }^{75}$ Whether or not these exceptions apply to research with biological samples is controversial. However, in the context of biobank-based research, it is reasonable to assume that data protection requirements pertain not only to personal data but also to biological samples, as they are a "vehicle of information", ${ }^{42}$

In fact, the Commission's current draft revision of the European Data Protection Directive explicitly grants exemptions for the processing of sensitive data in public health and scientific research. ${ }^{76}$ It also takes up recent developments in data-processing technologies by strengthening the "right to be forgotten". However, researchers and patient organizations see new obstacles for health research in the European Parliament's amendments to the Commission's draft. For example, the amended requirements that a subject reconsent to every new use of her data and give specific IC for them to be included in databases may be impractical for large-scale projects. ${ }^{77}$ Although negotiations between the Parliament and the Council of Ministers continue, it remains to be seen whether an appropriate balance between the right to privacy and the future improvement of health care can be struck.

Forsberg et $\mathrm{al}^{78}$ argue that current international biobanking research guidelines leave researchers in ambiguity, but, be that as it may, European regulations certainly give no clear guidance for research biobanking either. For example, Rec2006(4) has been criticized for disregarding the "sui generis nature of biobanks" $" 79$ and for overlapping with other instruments of the Council, such as the Additional Protocol to the Biomedicine Convention on research with human beings, concerning Biomedical Research. ${ }^{55,80}$ Therefore, researchers stress the need for a more consistent and coherent legal framework. ${ }^{10}$ Currently, a reexamination of Rec2006(4), in consultation with stakeholders, is ongoing. Issues being reevaluated include the transfer of samples and data across borders and the rise of WGS. ${ }^{81}$

\section{A typology of regulative approaches}

It is important to note that differences among European countries in their ethical and legal approaches to biobanking are the result of different research traditions and diverse sociopolitical, cultural, and religious norms. Not least because "biobanks naturally reflect the populations that make up of their resource", ${ }^{82}$ there are good reasons to appreciate different regulatory styles. ${ }^{42}$ For this reason, an analysis of the European context in terms of groups of countries seems most useful. ${ }^{63}$

Whether the research use of human tissues is regulated by laws passed specifically to control such activities, nonspecific existing laws, or means of soft law varies from country to country. Against this background, we can classify countries into three regulatory groups: countries with a specific law, countries with composite regulations of laws, often accompanied by soft law (eg, ethical guidelines), and countries with no domestic regulation where transnational provisions provide guidance (Table 3 ).

There is no evidence, however, that countries with specific biobanking laws have better or more comprehensive regulation than countries with composite regulations. Rather, each approach has its strengths and weaknesses. Estonia and Latvia, for example, have specific laws for the regulation of national genome programs, while other types of biobanks are in a legal gray zone. In Cyprus, which has no specific biobank law, the National Bioethics Committee provides a very successful example of soft regulation of biobank research. ${ }^{19}$

\section{Commonalities and differences in European countries' ethical and legal approaches}

The European countries feature several commonalities in their regulative approaches. ${ }^{42,63}$ Most require a donor's IC for the collection of specimens and data, at least if they allow the donor to be identified. In this regard, the European provisions, particularly the $\mathrm{OC}$, had a harmonizing effect. In

Table 3 Overview of regulative approaches to human tissue and biobank research in the EU

\begin{tabular}{|c|c|c|}
\hline $\begin{array}{l}\text { Laws specific to } \\
\text { human tissue/ } \\
\text { biobank research }\end{array}$ & $\begin{array}{l}\text { Composite } \\
\text { regulation of } \\
\text { human tissue/ } \\
\text { biobank research }\end{array}$ & $\begin{array}{l}\text { No national } \\
\text { regulation of } \\
\text { human tissuel } \\
\text { biobank research }\end{array}$ \\
\hline Belgium & Austria $^{\mathrm{a}}$ & Bulgaria \\
\hline Estonia & Cyprus $^{\mathrm{a}}$ & Croatia \\
\hline Finland & Denmark $^{\mathrm{a}}$ & Czech Republic \\
\hline Hungary & France $^{\mathrm{a}}$ & Malta \\
\hline Latvia & Germany $^{a}$ & Romania \\
\hline Lithuania & Greece $^{a}$ & Slovakia \\
\hline Portugal & Italy & \\
\hline Spain & Luxembourg & \\
\hline Sweden ${ }^{a}$ & the Netherlands & \\
\hline \multirow[t]{3}{*}{$\mathrm{UK}^{\mathrm{a}}$} & Poland & \\
\hline & Republic of Ireland ${ }^{\mathrm{a}}$ & \\
\hline & Slovenia $^{a}$ & \\
\hline
\end{tabular}

Note: aCountries with ethical recommendations in addition to legal provisions. 
Eastern Europe, for example, the OC led to the introduction of IC into health care systems as a general norm. ${ }^{63}$

Recently, a relaxation of specific IC requirements can be observed. Most countries accept broad consent, particularly for population biobanks, provided that certain safeguards are in place. For example, when obtaining an individual's IC, or secondary IC, is impossible or requires unreasonable effort, review by an REC is the default procedure in most countries. A similar approach is suggested by the draft proposal of the World Medical Association's Declaration on Ethical Considerations Regarding Health Databases and Biobanks, which is currently open for discussion.

However, there is no common rule for the involvement of RECs, and this has led to different approval procedures. ${ }^{42}$ Moreover, waiving IC requirements for the use of samples in secondary research is at least in tension with article 22 of the Rec2006(4), which calls for "appropriate information and consent procedures" in such cases. ${ }^{20}$

A donor's right to withdraw his consent is also widely accepted in Europe although spelled out in practice differently in different countries. The UK Biobank, for example, has a range of withdrawal options running from "no further contact" over "no further access" to "no further use", whereas in Sweden, researchers may still make use of the data from samples even after withdrawal of IC has excluded the samples from further research use. The implementation of IC in daily biobanking practice is also heterogeneous, even within a single country. Content analysis of consent forms in Germany, for example, has shown considerable variation in the issues that biobanks address. ${ }^{83}$ Research rules for residual tissues also vary across Europe. ${ }^{84,85}$ While some countries have an opt-out system for their use (eg, Denmark), others allow the waiver of IC, provided that the materials are anonymous and/or an REC has approved (eg, UK, Spain, and Cyprus).

Data protection is crucial in biobanking, and there is wide agreement among EU member states that donors' identities should not be disclosed to parties outside the biobank. However, the case in which the Swedish police's access to the national newborn-screening registry led to the apprehension of the murderer of the former Swedish minister Anna Lindh reveals the vulnerability of biobanks to unlawful access. ${ }^{86}$ Countries address this vulnerability in different ways. The UK Biobank, for example, stipulates that it will resist complying with such requests; ${ }^{82}$ the Estonian Genome Project explicitly prohibits access to state authorities; and, in Germany, the Ethics Council recommends the introduction of a "biobank secrecy". ${ }^{87}$
One widely used means to protect donors' privacy is the coding or double coding of samples and data. The data and the decoding key are stored separately, and only selected researchers have access to the latter. However, with the introduction of new technologies for large-scale genetic analyses, complete anonymization may no longer be feasible. ${ }^{88}$ However, from the perspective of researchers, complete anonymization may not even be desirable as recontacting donors is integral to biobank research. The Rec(2006)4 takes this into account by distinguishing between "identifiable" and "nonidentifiable materials". The latter is defined as "unlinked anonymized materials" that "do not allow, with reasonable efforts, the identification of the person concerned" (article 3). ${ }^{20}$ This definition has had an impact on several countries' regulations and led to less heterogeneity in terminology ${ }^{63}$ For example, most countries exempt unlinked anonymized materials from the more strict protective measures that apply to identifiable samples.

Another uniting feature in Europe is that biobanks must meet certain organizational requirements and are subject to legal oversight. Thus, only a few countries (eg, the UK and Iceland) stipulate the licensing of biobanks. The most common rule is that biobanks be accredited by the relevant national authority, like the Ministry of Health (eg, Portugal and Romania), the Ministry of Science and Innovation (Spain), or the Data Protection Authority (eg, Denmark and Greece). In addition, some countries require the evaluation of biobanks by an REC followed by notification of the appropriate ministry (eg, Norway and Sweden) or the approval of the Data Inspection Authority (eg, Lithuania). ${ }^{42}$ Even in those countries that require no accreditation, governments can exercise practical oversight. For example, because meeting Germany's high biobanking standards is costly, many institutions cannot afford to operate a biobank. Finally, several European countries (eg, Sweden, Spain, and Germany) have established national biobank registries to keep track of existing biobanks.

\section{Outlook}

Our analysis has shown that regulative approaches in European biobanking share commonalities on a range of issues. It would be an exaggeration to speak of a common European approach to biobanking, but common trends can be identified with regard to specific developments, eg, IC, population biobanks, and commercialization. At the same time, ethical and legal regulations on a range of issues, such as WGS and the handling of IHFs in biobank research, are still evolving and require further study. Most strikingly, many 
European documents covering human tissues focus on the therapeutic context, and their implications for research must be assessed carefully.

The need for harmonization is widely stressed if European biobanks are to be used efficiently. However, "harmonization" is rarely well defined and seems to express a range of unrealistic expectations. Given that the EU's legal provisions must be transposed into national laws, a complete unification or standardization of the ethical and legal frameworks for biobanking is not attainable. In particular, as European countries' regulatory approaches to biobanking are strongly influenced by their ethical, legal, and research traditions, there is no good in abandoning these organic frameworks. On the contrary, the most promising approach in the European context is to understand harmonization as a strategy that, instead of eliminating differences, seeks "to make differences compatible". ${ }^{89}$ In this way, existing regulatory differences among the EU's countries can spur institutional learning. Moreover, networking initiatives such as BBMRI-ERIC provide soft mechanisms that promote practical, ethical, and legal harmonization in European biobank research.

\section{Acknowledgments}

This review is based on findings from the Tiss. EU Project ("Evaluation of Legislation and Related Guidelines on the Procurement, Storage and Transfer of Human Tissues and Cells in the European Union - an Evidence-Based Impact Analysis"), which was funded by the EU's 7th Framework Programme from 2008 to 2011 and coordinated by Christian Lenk. Katharina Beier's work on this paper has been supported by the Research Program of the University Medical Center, University of Goettingen. The authors are indebted to Greg Sax for his editing.

\section{Disclosure}

The authors report no conflicts of interest in this work.

\section{References}

1. Hewitt RE. Biobanking: the foundation of personalized medicine. Curr Opin Oncol. 2011;23(1):112-119.

2. Yuille M, van Ommen G, Bréchot C, et al. Biobanking for Europe. Brief Bioinform. 2008;9(1):14-24.

3. Watson PH. Biobank classification: communicating biorepository diversity. Biopreserv Biobank. 2014;12(3):163-164.

4. Fransson MN, Rial-Sebbag E, Brochhausen M, et al. Toward a common language for biobanking. Eur J Hum Genet. 2015;23(1):22-28.

5. Hewitt R, Watson P. Defining biobank. Biopreserv Biobank. 2013;11(5): 309-315.

6. Shaw DM, Elger BS, Colledge F. What is a biobank? Differing definitions among biobank stakeholders. Clin Genet. 2014;85(3): 223-227.
7. Belgian law regarding the procurement and use of human body material destined for human medical applications or for scientific research purposes. Available from: http://www.ejustice.just.fgov.be/cgi_loi/ change_lg.pl?language $=$ fr\&la $=F \& c n=2008121944 \&$ table_name $=$ loi. Accessed June 5, 2015. French.

8. Portuguese Law no $12 / 2005$ of 26 th of January. Act on personal genetic information and information regarding health (unofficial English translation). Available from: https://www.eshg. org/fileadmin/www.eshg.org/documents/Europe/LegalWS/Portugal_Law-UnofficialEnglishTranslation.pdf. Accessed June 5, 2015.

9. Asslaber M, Zatloukal K. Biobanks: transnational, European and global networks. Brief Funct Genomic Proteomic. 2007;6(3):193-201.

10. Zika E, Paci D, Braun A, et al. A European survey on biobanks: trends and issues. Public Health Genomics. 2011;14(2):96-103.

11. Wichmann H, Kuhn KA, Waldenberger M, et al. Comprehensive catalog of European biobanks. Nat Biotechnol. 2011;29(9):795-797.

12. Meir K, Cohen Y, Mee B, et al. Biobank networking for dissemination of data and resources: an overview. BSAM. 2014;(2):29-42.

13. Harris JR, Burton P, Knoppers BM, et al. Toward a roadmap in global biobanking for health. Eur J Hum Genet. 2012;20(11):1105-1111.

14. Shickle D, Griffin M, El-Arifi K. Inter- and intra-biobank networks: classification of biobanks. Pathobiology. 2010;77(4):181-190.

15. Vaught J, Kelly A, Hewitt R. A review of international biobanks and networks: success factors and key benchmarks. Biopreserv Biobank. 2009;7(3):143-150.

16. van Ommen GJ, Törnwall $\mathrm{O}$, Bréchot $\mathrm{C}$, et al. BBMRI-ERIC as a resource for pharmaceutical and life science industries: the development of biobank-based Expert Centres. Eur J Hum Genet. 2015;23(7): 893-900.

17. Reichel J, Lind A, Hansson MG, et al. ERIC: a new governance tool for biobanking. Eur J Hum Genet. 2014;22(9):1055-1057.

18. Lenk C, Sándor J, Gordijn B, editors. Biobanks and Tissue Research: The Public, the Patient and the Regulation. Dordrecht, The Netherlands: Springer; 2011.

19. Beier K, Schnorrer S, Hoppe N, Lenk C, editors. The Ethical and Legal Regulation of Human Tissue and Biobank Research in Europe. Göttingen, Germany: Universitätsverlag Göttingen; 2011.

20. Recommendation Rec(2006) 4 of the Committee of Ministers to member states on research on biological materials of human origin. Available from: https://wcd.coe.int/ViewDoc.jsp?id=977859. Accessed June 5, 2015.

21. Gibbons SC, Helgason HH, Kaye J, et al. Lessons from European population genetic databases: comparing the law in Estonia, Iceland, Sweden and the United Kingdom. Eur J Health Law. 2005;12(2): 103-133.

22. Sak J, Pawlikowski J, Goniewicz M, et al. Population biobanking in selected European countries and proposed model for a Polish national DNA bank. J Appl Genet. 2012;53(2):159-165.

23. Rudan I, Marusić A, Janković S, et al. "10001 Dalmatians": Croatia launches its national biobank. Croat Med J. 2009;50(1):4-6.

24. Wichmann H, Kaaks R, Hoffmann W, et al. Die Nationale Kohorte [The German National Cohort]. Bundesgesundheitsblatt, Gesundheitsforschung, Gesundheitsschutz. 2012;55(6-7):781-787. German.

25. Kattel R, Suurna M. The rise and fall of the Estonian genome project. Stud Ethics Law Technol. 2008;2(2):1-22.

26. Sándor J, Bárd P. The Legal Regulation of Biobanks. National Report: Estonia. CELAB Paper Series, Number 5. Hungary: CELAB; 2009.

27. Pálsson G. The rise and fall of a biobank: the case of Iceland. In: Gottweis H, Petersen A, editors. Biobanks. Governance in Comparative Perspective. London, NY: Routledge; 2008:41-55.

28. Simeon-Dubach D, Watson P. Biobanking 3.0: evidence based and customer focused biobanking. Clin Biochem. 2014;47(4-5): 300-308.

29. Kettis-Lindblad A, Ring L, Viberth E, et al. Genetic research and donation of tissue samples to biobanks. What do potential sample donors in the Swedish general public think? Eur J Public Health. 2006; 16(4):433-440. 
30. Porteri C, Pasqualetti P, Togni E, et al. Public's attitudes on participation in a biobank for research: an Italian survey. BMC Med Ethics. 2014;15: 81-90.

31. Gaskell G, Gottweis H, Starkbaum J, et al. Publics and biobanks: Pan-European diversity and the challenge of responsible innovation. Eur J Hum Genet. 2013;21(1):14-20.

32. Stjernschantz Forsberg J, Hansson MG, Eriksson S. Why participating in (certain) scientific research is a moral duty. J Med Ethics. 2014; 40(5):325-328.

33. Petersen I, Desmedt C, Harris A, et al. Informed consent, biobank research, and locality: perceptions of breast cancer patients in three European countries. J Empir Res Hum Res Ethics. 2014;9(3): $48-55$.

34. Kaye J, Curren L, Anderson N, et al. From patients to partners: participant-centric initiatives in biomedical research. Nat Rev Genet. 2012;13(5):371-376.

35. BBMRI. Biobanks and the Public: Governing Biomedical Research Resources in Europe (BBMRI): ELSI Report; 2013. Available from: http://bbmri-eric.eu/documents/10181/83482/ BBMRI+Biobanks+and+the+Public.pdf/17fa1bc4-2c4d-4f1 f-9ce8e5874989d93f. Accessed June 5, 2015.

36. Caulfield T, Upshur REG, Daar A. DNA databanks and consent: a suggested policy option involving an authorization model. BMC. 2003;4: $1-4$.

37. Árnason V. Coding and consent: moral challenges of the database project in Iceland. Bioethics. 2004;18(1):27-49.

38. Bullock E, Widdows $\mathrm{H}$. Reconsidering consent and biobanking. In: Lenk C, Sándor J, Gordijn B, editors. Biobanks and Tissue Research: The Public, the Patient and the Regulation. Dordrecht, The Netherlands: Springer; 2011:111-126.

39. Kaye J, Whitley EA, Lund D, et al. Dynamic consent: a patient interface for twenty-first century research networks. Eur J Hum Genet. 2015; 23(2):14-16.

40. Steinsbekk KS, Kåre Myskja B, Solberg B. Broad consent versus dynamic consent in biobank research: is passive participation an ethical problem? Eur J Hum Genet. 2013;21(9):897-902.

41. Prainsack B, Buyx A. A solidarity-based approach to the governance of research biobanks. Med Law Rev. 2013;21(1):71-91.

42. European Commission. Biobanks for Europe. A Challenge for Governance; 2012. Available from: http://www.coe.int/t/dg3/ healthbioethic/Activities/10_Biobanks/biobanks_for_Europe.pdf. Accessed June 5, 2015.

43. Johnsson L. Trust in Biobank Research. Meaning and Moral Significance [dissertation]. Accra, Ghana: Uppsala University; 2013.

44. Levitt M. Relating to participants: how close do biobanks and donors really want to be? Health Care Anal. 2011;19(3):220-230.

45. Colledge F, Elger B, Howard HC. A review of the barriers to sharing in biobanking. Biopreserv Biobank. 2013;11(6):339-346.

46. Zatloukal K, Vaught J. What are the next steps to overcoming roadblocks to transnational biobank collaboration? Biopreserv Biobank. 2012; $10(1): 2-3$

47. Goebel JW, Pickardt T, Bedau M, et al. Legal and ethical consequences of international biobanking from a national perspective: the German BMB-EUCoop Project. Eur J Hum Genet. 2010;18:522-525.

48. Zika E, Paci D, Schulte in den Bäumen T, et al. Biobanks in Europe: Prospects for Harmonisation and Networking. JRC Scientific and Technical Reports. Spain: European Commission; 2010. Available from: http://ipts.jrc.ec.europa.eu/publications/pub.cfm?id=3259. Accessed June 5, 2015.

49. Bovenberg J. How to achieve 'free movement of tissue' in the European research area. In: Lenk C, Beier K, Hoppe N, Wiesemann C, editors. Human Tissue Research - A Discussion of the Ethical and Legal Challenges from a European Perspective. Oxford, UK: Oxford University Press; 2011:127-138.

50. Hens K, Lévesque E, Dierickx K. Children and biobanks: a review of the ethical and legal discussion. Hum Genet. 2011;130:403-413.
51. Council of Europe. Convention for the Protection of Human Rights and Dignity of the Human Being with regard to the Application of Biology and Medicine: Convention on Human Rights and Biomedicine. (Oviedo Convention) CETS 164; 1997. Available from: http://conventions.coe. int/Treaty/en/Treaties/Html/164.htm. Accessed June 5, 2015.

52. Wendler D. The assent requirement in pediatric research. In: Emanuel EJ, editor: The Oxford Textbook of Clinical Research Ethics. Oxford: University Press; 2008:661-669.

53. EU Ad Hoc Group. Ethical Considerations for Clinical Trials on Medicinal Products Conducted with the Paediatric Population; 2008. Available from: ftp://ftp.cordis.europa.eu/pub/fp7/docs/ethicalconsiderations-paediatrics_en.pdf. Accessed July 1, 2015.

54. van El CG, Cornel MC, Borry P, et al. Whole-genome sequencing in health care. Recommendations of the European Society of Human Genetics. Eur J Hum Genet. 2013;21:580-584.

55. Council of Europe. Additional Protocol to the Convention on Human Rights and Biomedicine, concerning Genetic Testing for Health Purposes. CETS 203; 2008. Available from: http://conventions.coe. int/Treaty/en/Treaties/Html/203.htm. Accessed July 1, 2015.

56. Council of Europe. Explanatory Report to the Additional Protocol to the Convention on Human Rights and Biomedicine, concerning Genetic Testing for Health Purposes; 2008. Available from: http:// conventions.coe.int/Treaty/EN/Reports/Html/203.htm. Accessed July $1,2015$.

57. EURAT Project Group. Eckpunkte für eine Heidelberger Praxis der Ganzgenomsequenzierung [Cornerstones for a Heidelberg Practice of Whole Genome Sequencing]; 2013. Available from: http://www.marsiliuskolleg.uni-heidelberg.de/md/einrichtungen/mk/presse/stellungnahme_ heidelberger_praxis_der_ganzgenomsequenzierungl_2013-06-12.pdf. Accessed June 16, 2015. German.

58. Deutsche Gesellschaft für Humangenetik e.V. Stellungnahme der Deutschen Gesellschaft für Humangenetik zu genetischen Zusatzbefunden in Diagnostik und Forschung [Opinion of the German Society for Human Genetics on Genetic Incidental Findings in Diagnostics and Research]; 2013. Available from: http://www.gfhev.de/de/leitlinien/ LL_und_Stellungnahmen/2015_03_26_GfH-Olaparib-Stellungnahme. pdf. Accessed July 1, 2015. German.

59. Royal College of Physicians, Royal College of Pathologists and British Society for Human Genetics. Consent and Confidentiality in Clinical Genetic Practice: Guidance on Genetic Testing and Sharing Genetic Information: Report of the Joint Committee on Medical Genetics. 2nd ed. London, UK: RCP, RCPath; 2011. Available from: http://www. bsgm.org.uk/media/678746/consent_and_confidentiality_2011.pdf. Accessed July 1, 2015.

60. Lenk C, Frommeld D. Different concepts and models of information for family-relevant genetic findings: comparison and ethical analysis. Med Health Care Philos. 2015;18(3):393-408.

61. World Medical Association. Ethical Principles for Medical Research Involving Human Subjects. Fortaleza, Brazil: World Medical Association; 2013. Available from: http://www.wma.net/ en/30publications/10policies/b3/. Accessed July 1, 2015.

62. Lenk C. Taking solidarity seriously: do biobank institutions have a moral obligation to inform their patients on incidental health findings? In: Lenk C, Beier K, Hoppe N, Wiesemann C, editors. Human Tissue Research - A Discussion of the Ethical and Legal Challenges from a European Perspective. Oxford, UK: Oxford University Press; 2010:55-64.

63. Beier K, Lenk C. A Unified European approach on tissue research and biobanking? A comparison. In: Lenk C, Sándor J, Gordijn B, editors. Biobanks and Tissue Research: The Public, the Patient and the Regulation. Dordrecht, The Netherlands: Springer; 2011:143-164.

64. Caulfield T, Burningham S, Joly Y, et al. A review of the key issues associated with the commercialization of biobanks. J Law Biosci. 2014; 1(1):94-110.

65. Steinsbekk KS, Ursin LO, Skolbekken J, et al. We're not in it for the money-lay people's moral intuitions on commercial use of 'their' biobank. Med Health Care Philos. 2013;16(2):151-162. 
66. Lenk $\mathrm{C}$, Beier $\mathrm{K}$. Is the commercialisation of human tissue and body material forbidden in the countries of the European Union? $\mathrm{J} \mathrm{Med}$ Ethics. 2012;38(6):342-346.

67. Evers K, Forsberg J, Hansson M. Commercialization of biobanks. Biopreserv Biobank. 2012;10(1):45-47.

68. Pirnay J, Vanderkelen A, Ectors N, et al. Beware of the commercialization of human cells and tissues: situation in the European Union. Cell Tissue Bank. 2012;13(3):487-498.

69. Petrini C. Between altruism and commercialisation: some ethical aspects of blood donation. Ann Ist Super Sanita. 2013;49(4):412-416.

70. Bellevier F, Noiville C. The circulation of human body parts and products: when exclusive property rights mask the issue of access. In: Lenk C, Sándor J, Gordijn B, editors. Biobanks and Tissue Research: The Public, the Patient and the Regulation. Dordrecht, The Netherlands: Springer; 2011:111-126.

71. Harmon, SHE. Yearworth v. North Bristol NHS trust: a property case of uncertain significance? Med Health Care Philos. 2010; 13(4):343-350.

72. Hoeyer KL. Commercialization of tissue-based research: time to move beyond the gift/market dichotomy. Biopreserv Biobank. 2013; 11(6):397-398.

73. Hofman P, Bréchot C, Zatloukal K, et al. Public-private relationships in biobanking: a still underestimated key component of open innovation. Virchows Arch. 2014;464(1):3-9.

74. Calzolari A, Napolitano M, Bravo E. Review of the Italian current legislation on research biobanking activities on the eve of the participation of national biobanks' network in the legal consortium BBMRI-ERIC. Biopreserv Biobank. 2013;11(2):124-128.

75. Directive 95/46/EC of the European Parliament and of the Council of 24 October 1995 on the protection of individuals with regard to the processing of personal data and on the free movement of such data. Available from: http://eur-lex.europa.eu/LexUriServ/LexUriServ.do? uri=CELEX:31995L0046:en:HTML. Accessed June 5, 2015.

76. Di Iorio CT, Carinci F, Oderkirk J. Health research and systems' governance are at risk: should the right to data protection override health? J Med Ethics. 2014;40(7):488-492.

77. European Parliament legislative resolution of 12 March 2014 on the proposal for a regulation of the European Parliament and of the Council on the protection of individuals with regard to the processing of personal data and on the free movement of such data (General Data Protection Regulation). Available from: http://www.europarl. europa.eu/sides/getDoc.do?pubRef=-//EP//TEXT+TA+P7-TA-20140212+0+DOC+XML+V0//EN. Accessed June 5, 2015.
78. Forsberg JS, Hansson MG, Evers K. International guidelines on biobank research leave researchers in ambiguity: why is this so? Eur JEpidemiol. 2013;28(6):449-451.

79. Harmon, SHE. Council of Europe: the recommendation on research on biological materials of human origin: another brick in the wall. Eur $J$ Health Law. 2006;13(3):293-301.

80. Nys H. Research on human biological materials and the Council of Europe: some unanswered questions, overlaps and empty boxes. Eur J Health Law. 2008;15(1):1-6.

81. Council of Europe. Biobanks. Re-examination of Recommendation (2006)4. Available from: http://www.coe.int/t/dg3/healthbioethic/ Activities/10_Biobanks/default_en.asp. Accessed June 5, 2015.

82. Wallace S, Bédard K, Kent A, et al. Governance mechanisms and population biobanks: building a framework for trust. GenEditorial. 2008;6(2):1-11.

83. Hirschberg I, Knüppel H, Strech D. Practice variation across consent templates for biobank research. A survey of German biobanks. Front Genet. 2013;4:1-8.

84. Caenazzo L, Tozzo P, Pegoraro R. Biobanking research on oncological residual material: a framework between the rights of the individual and the interest of society. BMC Med Ethics. 2013;14:17.

85. van Veen E, Riegman PHJ, Dinjens WNM, et al. TuBaFrost 3: regulatory and ethical issues on the exchange of residual tissue for research across Europe. Eur J Cancer. 2006;42(17):2914-2923.

86. Ansell R, Rasmusson B. A Swedish perspective. Biosocieties. 2008;3(1):88-92.

87. German Ethics' Council. Human Biobanks for Research. Opinion; 2010. Available from: http://www.ethikrat.org/files/der_opinion_humanbiobanks.pdf. Accessed June 5, 2015.

88. Sándor J, Bárd P. Anonymity and privacy in biobanking. In: Lenk C, Sándor J, Gordijn B, editors. Biobanks and Tissue Research. The Public, the Patient, and the Regulation. Dordrecht, The Netherlands: Springer; 2011:213-230.

89. Tassé A. From ICH to IBH in biobanking? A legal perspective on harmonization, standardization and unification. Stud Ethics Law Technol. 2013;7(1). doi: 10.1515/1941-6008.1180.
Journal of Biorepository Science for Applied Medicine

\section{Publish your work in this journal}

The Journal of Biorepository Science for Applied Medicine is an international, peerreviewed, open access journal that focuses on new developments and advances in the emerging and evolving field of biorepository science. This includes biospecimen procurement, processing, preservation, and banking for application to applied medicine. The Journal invites submission of manuscripts which address these aspects in addition to systems logic, clinical throughput and ethical issues pertaining to application of

\section{Dovepress}

biorepositories and their effects on clinical medicine. The journal is characterized by the rapid reporting of reviews, original research, methodologies, technologies and analytics in this subject area. The manuscript management system is completely online and includes a very quick and fair peer-review system, which is all easy to use. Visit http:/ www.dovepress.com/testimonials.php to read real quotes from published authors. 